Article

\title{
Enhancement of Dynamic Damping in Eco-Friendly Railway Concrete Sleepers Using Waste-Tyre Crumb Rubber
}

\author{
Sakdirat Kaewunruen ${ }^{1,2, *(\mathbb{D})}$, Dan $\mathrm{Li}^{2}{ }^{2}$ Yu Chen ${ }^{2}$ and Zhechun Xiang ${ }^{2}$ \\ 1 Birmingham Centre for Railway Research and Education, University of Birmingham, \\ Birmingham B152TT, UK \\ 2 Department of Civil Engineering, School of Engineering, University of Birmingham, \\ Birmingham B152TT, UK; DXL561@student.bham.ac.uk (D.L.); chenyu304304@outlook.com (Y.C.); \\ 15372291781@163.com (Z.X.) \\ * Correspondence: s.kaewunruen@bham.ac.uk; Tel.: +44-(0)-1214-142-670
}

Received: 20 June 2018; Accepted: 6 July 2018; Published: 9 July 2018

\begin{abstract}
There is no doubt that the use of waste rubber in concrete applications is a genius alternative because Styrene is the main component of rubber, which has a strong toxicity and is harmful to humans. Therefore, it will significantly reduce impacts on the environment when waste rubber can be recycled for genuine uses. In this paper, the dynamic properties of high-strength rubberised concrete have been investigated by carrying out various experiments to retain the compressive strength, tensile strength, flexural strength, electrical resistivity, and damping characteristics by replacing fine aggregates with micro-scale crumb rubber. Over 20 variations of concrete mixes have been performed. The experimental results confirm that a decrease in the compressive strength can be expected when the rubber content is increased. The new findings demonstrate that the high-strength concrete can be enhanced by optimal rubber particles in order to improve splitting tensile and flexural strengths, damping properties, and electrical resistivity. It is therefore recommended to consider the use of rubberised concrete (up to $10 \mathrm{wt}$ \% crumb rubber) in designing railway sleepers as this will improve the service life of railway track systems and reduce wastes to the environment.
\end{abstract}

Keywords: crumb rubber; high-strength concrete; damping; dynamic moduli; railway application; recycled material

\section{Introduction}

At the beginning of the last century, with the development of science and technology, the reduction of forest resources led to the production of steel and concrete railway sleepers rather than wood [1-3]. Since railway sleepers are effective but expensive, reinforced concrete has been used as a reliable and more efficient material for railway sleepers since the 1950s [4]. On the other hand, the rapid development of the automotive industry has led to the rapid development of the rubber tire industry and brought about the dilemma of how to deal with rubber waste that poses a serious threat to the environment.

Recently, many researches have proposed and encouraged the use of waste rubber in concrete to improve its performance [5-7]. More precisely, in the railway sector the rubber concrete sleepers have known a high-demand due to its efficiency in high-intensity pressure vibration environment. In this study, the crumb rubber is replacing the fine aggregates in the concrete sleepers in order to evaluate their ability to absorb the vibration energy. While it is expected to have a material with better performances than conventional concrete, the reason behind this evaluation is to create a rubber 
concrete that can maintain its strength at an acceptable level, thus enhancing the performance and sustainability of the railway track systems exposed to high-intensity impact loading conditions [8-10].

The purpose of this paper is to highlight the sensitivity of dynamic properties of the high-strength concrete to crumb rubber inclusion as well as its capability in meeting the standards of railway concrete sleepers' manufacturing. Different proportions of crumb rubber with different particle sizes $(75,180$, and $400 \mu \mathrm{m}$ ) have been used in order to analyse their effects on the compressive strength, splitting tensile and flexural strengths, electrical resistivity and damping properties of the rubberised concrete.

\section{Railway Applications}

Conventional rail track structure can be divided into superstructure and substructure (Figure 1). The superstructure includes rails, rail pads, fastening system and rail sleepers. The substructure consists of ballast, sub-ballast and formation. Railway sleeper is one of the most important safety-critical components of the track structure. The main functions of rail sleeper are to transfer vertical loads from rails to foundation and maintain rail gauge. According to Cai [11], the sleepers are laid horizontally under the rail and placed on the track bed, bearing the pressure from the rail and spread it all over the ballast bed.

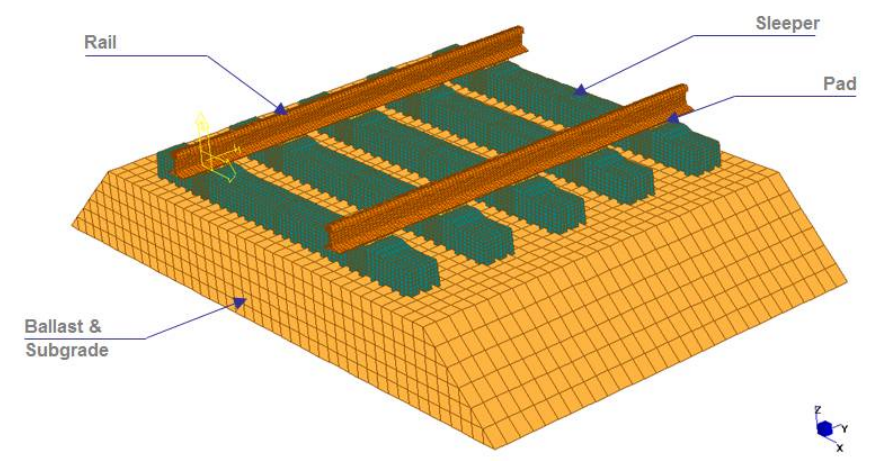

Figure 1. Components of railway tracks.

The sleepers are usually manufactured by timber or concrete composite nowadays. Timber sleepers are often used in North America which have superior elasticity, better mitigation and absorption of vibration, but their life cycle is no more able to meet today's market requirements. Consequently, concrete sleepers have recently become the most widely used due to their low maintenance cost and longer life cycle in comparison with timber sleepers [12].

The railway concrete sleepers are expected to service for 50 years $[13,14]$. However, in practice the service life of concrete sleepers barely meet the design requirement due to many causes. In order to determine the total energy needed for the failure of railway concrete sleepers under sudden load, their dynamic response was investigated. It has been found that the railway concrete sleepers' impact resistance was more affected under splitting mode as there was a lack of bonding between concrete and steel bars under dynamic circumstances [15]. The most critical problems related to failure of concrete sleepers were surveyed by Stuart. The survey reported that concrete sleepers cracking from dynamic loads were significant [16]. Their durability is reduced as the cracks start to appear which increase the chance of fatigue failure. The cracks in sleepers are initiated when they experience severe loading conditions such as high-magnitude wheel loads created by ruthless wheels or rail abnormalities [17]. It has therefore been observed that the use of crumb rubber in concrete could minimize the damage of cracks in sleepers, as the crumb rubber concrete has shown significant toughness properties and impact resistance. The elastic properties and fatigue resistance will also improve by using crumb rubber in concrete [18]. The previous research conducted by Sallam et al. [19] revealed that resistance of crack under impact loading will be improved in the presence of rubber particle. Hameed and Shashikala [18] indicated that the stiffness of concrete will be increased when containing crumb 
rubber under cyclic loads. The outcome of this research has indicated the dynamic property of crumb rubber concrete through various experiments which provide important data for future railway sleeper durability design.

\section{Methods}

\subsection{Rubber Wastes and Their Applications}

The large amount of abandoned waste tyres (Figure 2) while handled and removed quickly will certainly impact the environment. Common solid waste disposal methods like incinerated and landfilled are not suitable for this kind of waste as they lead to the release of toxic substances which results in serious contaminations of underground water systems. The thousands of hectares of landfills not only occupy sites that can have better usages, but also contribute to bacteria and mosquitoes breeding, causing infectious diseases and blazes [20].

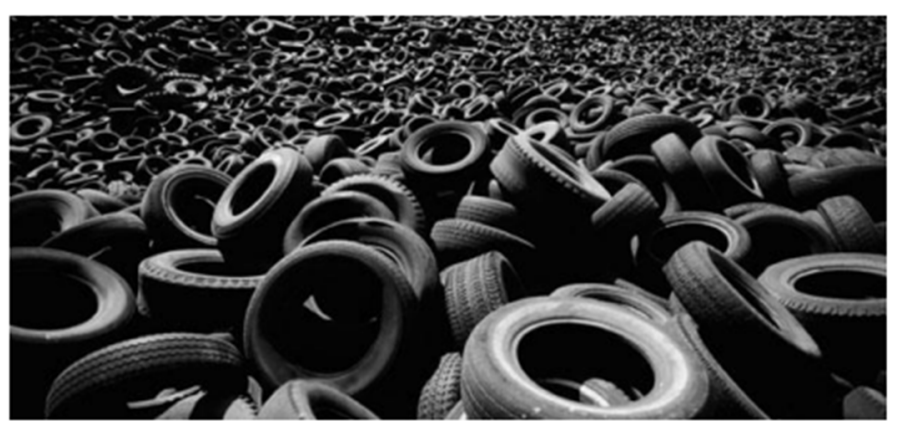

Figure 2. Waste tyres.

As early as 1976, there was a patent for old tyres usage in the United States [21,22]. Nowadays, more granulation methods appeared, such as extraction of steel fibres from waste tyres as reinforcement in concrete is now possible [6]. Some researchers reported that the crumb rubber, when added to ballasted tracks, resulted in better absorption of the vibration impact energy and improved their life cycle [23]. More researches devoted to the possibility of partially replacing aggregates with rubber particles (Figure 3) as an eco-friendly alternative while dealing with rubber waste [24], and also improving the concrete damping characteristics [25].

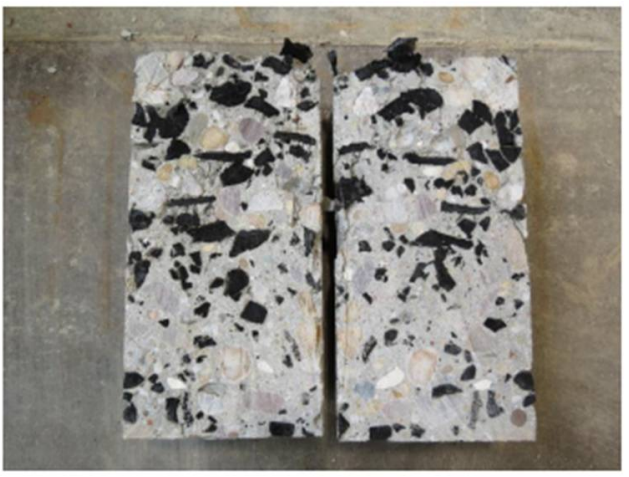

Figure 3. Crumb rubber concrete.

\subsection{Relevant Previous Studies}

Most studies have shown that the replacement of the fine aggregates by crumb rubber in concrete will reduce its strength to a certain extent, and the degree of decrease in strength depends on both the particle size and the amount of addition [26]. Still, other studies reported many other benefits 
of using rubber in concrete. Rubber particles can act as an air-entraining agent and hence providing concrete with a better freeze-cycle protection [27]. Thermal resistance also presents a challenge for concrete sleepers, and since rubber has good heat insulation it was found that the crumb rubber can increase the thermal resistance of concrete to about $18.52 \%$ [28]. Conventional concrete has better fire resistance than crumb rubber concrete as the rubber is a flammable material and its particles on the concrete surfaces can easily be burnt [29]. The dynamic properties are very important in the railway track design process. For concrete sleepers, cracking could be caused by wheel-rail interaction force which can be divided into dynamic load and impact load [30]. Dynamic load is wheel-rail interaction under normal situation, whereas impact load is also wheel-rail interaction caused by defects in wheel or rail. In durability design, sleepers need to withstand dynamic load and impact load. However, the dynamic testing data of crumb rubber concrete is not enough for concrete sleeper design. Therefore, investigation of dynamic properties is necessary for new material concrete sleeper design [31].

\section{Materials}

The emphasis of this study is placed on the application of recycled crumb rubber to enhance dynamic damping of structural concrete for railway applications. To enable the industry application, specific requirements must be complied (e.g., EN 13230 [32]). The materials for the concrete mix are thus specifically chosen to meet standard requirements.

\subsection{Cement}

As described in BS EN 197-1 [33], the Portland Cement Type I (CEM I) could be used to mix concrete which has a characteristic strength of $55 \mathrm{MPa}$.

\subsection{Silica Fume}

Silica fume is a grey powder that belongs to a broad class of siliceous and aluminous materials called "Pozzolans", which plays a particular role in filling the pores between the cement. Adding the right amount of silica fume contributes to improving the compressive and flexural strengths, impermeability, corrosion/impact resistances. These improvements are due to the consummation of calcium hydroxides, produced by the hydration of cement, by the silicon dioxide $\mathrm{SiO}_{2}$ [34] present in the composition of the silica fume as summarized in Table 1 . The use of silica fume in this study is to compensate the loss of strength when crumb rubber is used.

Table 1. Chemical and Physical Properties of Undensified Silica Fume [35].

\begin{tabular}{ccc}
\hline No. & Properties & Value \\
\hline 1 & $\mathrm{SiO}_{2}$ & Minimum $90 \%$ \\
2 & Loss of Ignition & Maximum $3 \%$ \\
3 & Coarse Particles $>45 \mu \mathrm{m}$ & Maximum $1.5 \%$ (tested on undensified) \\
4 & Bulk Density (U) & $200-350 \mathrm{~kg} / \mathrm{m}^{3}$ \\
5 & Bulk Density (D) & $500-700 \mathrm{~kg} / \mathrm{m}^{3}$ \\
\hline
\end{tabular}

\subsection{Coarse Aggregates}

Coarse aggregate refers to pebbles and gravel, while fine aggregate refers to natural sand and artificial sand. Aggregates with a particle size greater than $4.75 \mathrm{~mm}$ are called coarse aggregates and aggregates with a diameter of $4.75 \mathrm{~mm}$ or less are called fine aggregates. Using a vibrating sieve to screen out usable gravels, the gradation table is produced as shown in Table 2. For concrete sleepers, all aggregates should comply with BS EN 12620 [36]. 
Table 2. Gradation of aggregates.

\begin{tabular}{cccccc}
\hline No. & Sieves $(\mathbf{m m})$ & Weight Retained $(\mathbf{g})$ & \% Retained & Cumulative Retained & \% Finer \\
\hline 1 & 20 & 0 & $0 \%$ & 0 & $100 \%$ \\
2 & 16 & 0 & $0 \%$ & 0 & $100 \%$ \\
3 & 10 & 835 & $21 \%$ & $21 \%$ & $79 \%$ \\
4 & 6.7 & 2710 & $67.5 \%$ & $88.5 \%$ & $11.5 \%$ \\
5 & 4.75 & 355 & $9 \%$ & $97.5 \%$ & $2.5 \%$ \\
6 & Base & 100 & $2.5 \%$ & $100 \%$ & $0 \%$ \\
& Total & $4000 \mathrm{~g}$ & & & \\
\hline
\end{tabular}

\subsection{Water}

The water used to mix concrete should be clean and easy to obtain on site, in accordance to BS EN 206-1 [37].

\subsection{Admixture}

Concrete admixtures are substances, once added to the mixture, that improve and adjust the performance of concrete. Typically, according to BS EN 934-2 [33], they cannot be added in excess of $5 \%$ of the cement content. The most common such admixtures are water-reducing agents, set retarder, air-entraining admixture, etc.

\subsection{Concrete}

The general performance of concrete sleepers should conform to BS EN 206-1 [37], which means cylinder samples compressive strength not below $55 \mathrm{MPa}$, cement content over $300 \mathrm{~kg} / \mathrm{m}^{3}$ and a maximum water-cement ratio of 0.45 cannot be exceeded. After casting, the concrete samples must be covered with plastic sheet for $24 \mathrm{~h}$, and then placed in a water tank for 7 and 28 days prior for testing. The mix design (see Table 3 ) has been further developed from previous studies to ensure that the concrete could satisfy the minimum requirements $[32,33,38]$. A pilot test has been conducted to achieve the requirement and reveal an appropriate ratio between water and binder (cement + silica fume). The ration has been retained for all mixes to ensure that the comparison could be rationalised.

Table 3. Concrete mix design.

\begin{tabular}{|c|c|c|c|c|c|c|c|}
\hline \multicolumn{6}{|c|}{ Main Components } & Mixes A & \multirow{2}{*}{$\begin{array}{c}\text { Mixes B } \\
\text { Crumb Rubber } \\
\text { CR }(75 \mu \mathrm{m})\end{array}$} \\
\hline Ingredients $\mathrm{kg} / \mathrm{m}^{3}$ & Cement & Water & Gravel & Sand & $\begin{array}{l}\text { Silica } \\
\text { Fume SF }\end{array}$ & $\begin{array}{c}\text { Crumb Rubber } \\
\text { CR (180 \& } 400 \mu \mathrm{m})\end{array}$ & \\
\hline SF-0 $\%$, CR-0 $\%$ & 530 & 233 & 986 & 630 & - & - & - \\
\hline SF- $5 \%$, CR-0 $\%$ & 503 & 233 & 986 & 630 & 27 & - & - \\
\hline SF-10\%, CR- $0 \%$ & 477 & 233 & 986 & 630 & 53 & - & - \\
\hline SF-5\%, CR-5\% & 503 & 233 & 986 & 598 & 27 & 32 & 32 \\
\hline SF-10\%, CR-5\% & 477 & 233 & 986 & 598 & 53 & 32 & 32 \\
\hline SF-5\%, CR-10\% & 503 & 233 & 986 & 567 & 27 & 63 & 63 \\
\hline SF- $10 \%$, CR- $10 \%$ & 477 & 233 & 986 & 567 & 53 & 63 & 63 \\
\hline
\end{tabular}

\section{Experimental Results and Discussion}

Based on the design requirements of the railway concrete sleepers that comply with the British Standards BS EN 206-1 [37], and on the theory described in the "Design of Normal Concrete Mixes" [39], 133 specimens were casted using different materials' proportions. Silica fume is used as a partial replacement of the cement content and the crumb rubber as an alternative aggregate by replacing different amounts of fine aggregates. One hundred and fourteen specimens were characterized by the use of the crumb rubber, half of them were made using a mix of 180 and 400 micron crumb rubber (Mixes A), and the other half was mixed using 75 micron crumb rubber (Mixes B), as shown in Figure 4 and Table 3. 

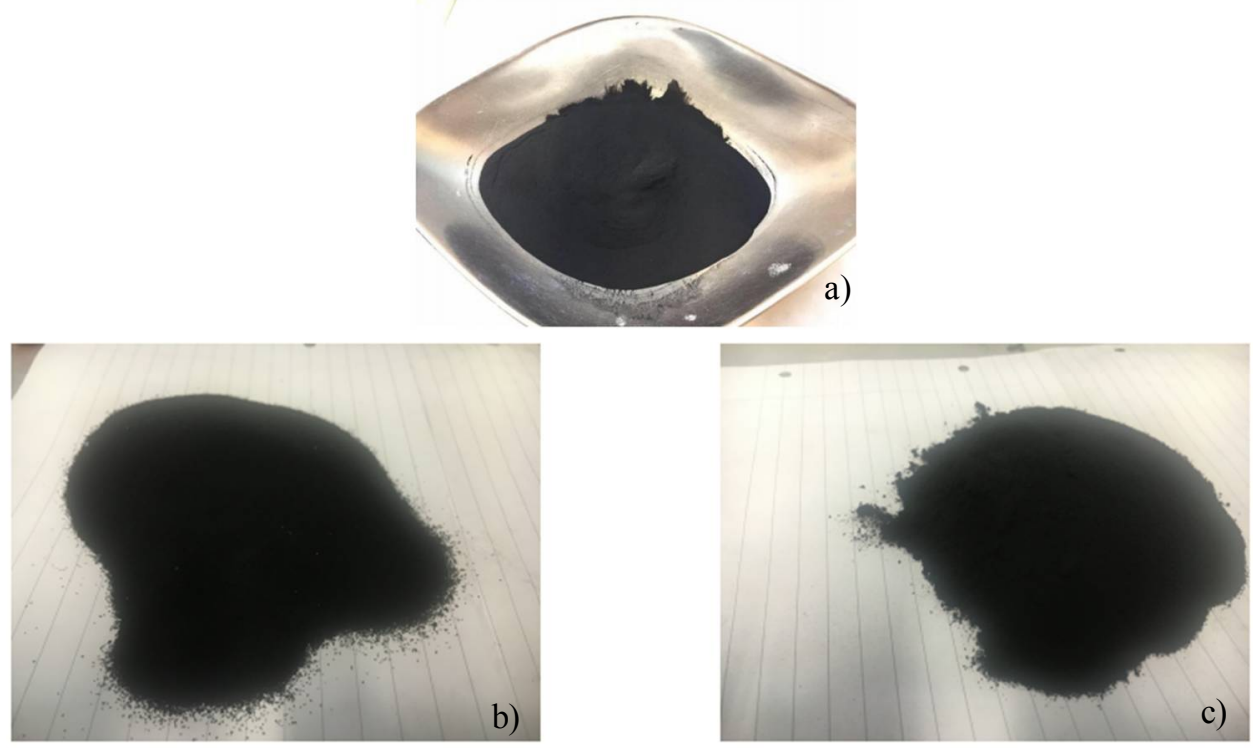

Figure 4. Rubber Powder ((a) $75 \mu \mathrm{m}$; (b) $400 \mu \mathrm{m}$; and (c) $180 \mu \mathrm{m}$ particle size, respectively).

Serviceability tests were conducted after each mix as shown in Figure 5. Then, they were cured in water (see Figure 6). For each single batch, there were 19 samples manufactured. Once the concrete has been mixed, it was poured directly into different shaped moulds: $100 \mathrm{~mm}$ cube, $\Phi 100 \times$ L200 mm cylinder, W100 $\times$ H100 $\times$ L500 mm prism, and W45 $\times$ H20 $\times$ L120 mm prism, each shape corresponding to the compressive strength testing (CS), splitting tensile strength testing (STS), flexural strength testing (FS), and electrical resistivity testing (ER) and vibration testing (VT), respectively as shown in Table 4. In order to provide good curing conditions, the samples are demoulded after $24 \mathrm{~h}$ and placed in a tank at appropriate temperature, then removed after 7 and 28 days respectively to carry out tests.
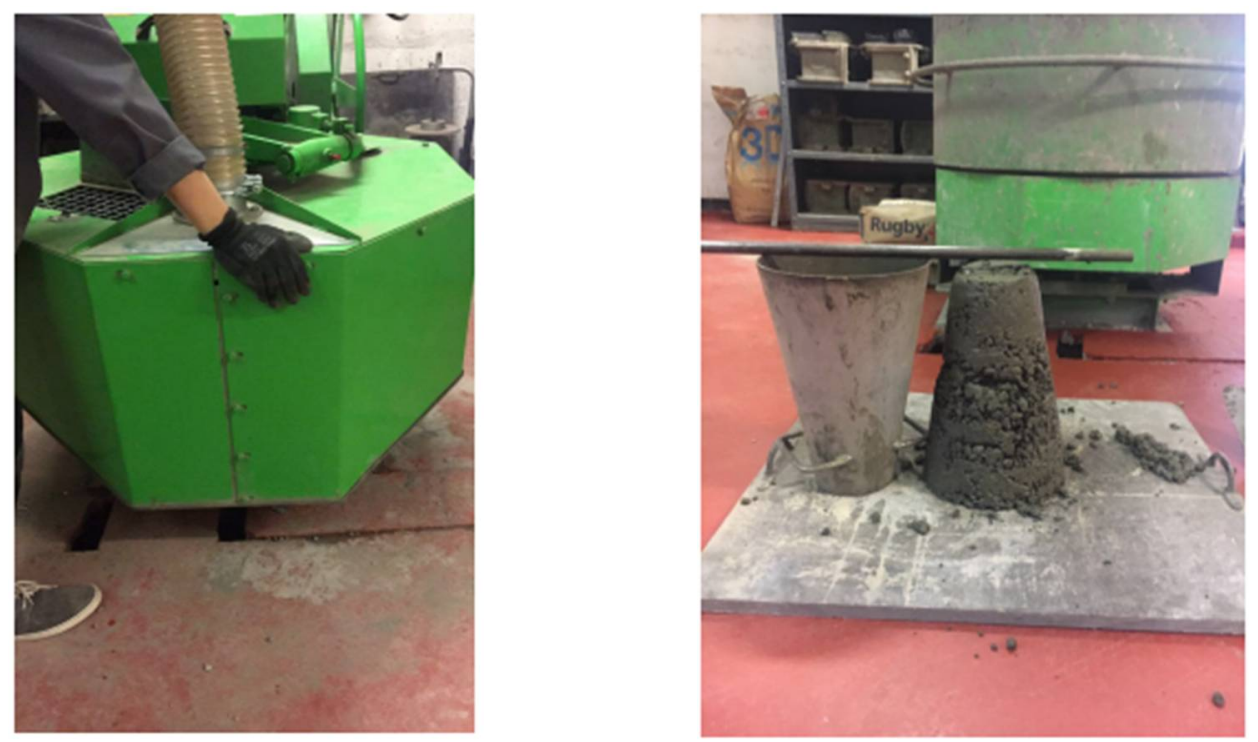

Figure 5. Concrete mixer (left); concrete slump test (right). 

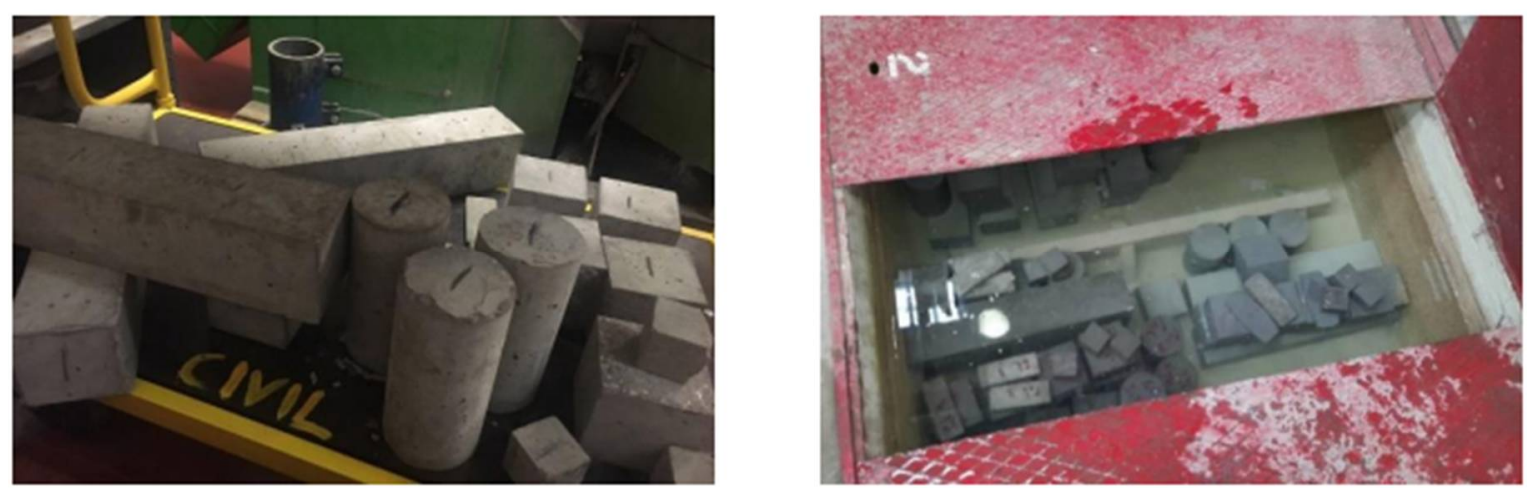

Figure 6. Specimen shapes (left); curing tank (right).

Table 4. Types of moulds and corresponding tests.

\begin{tabular}{ccc}
\hline Mould Type & Number of Samples per Mix & Type of Test \\
\hline Cube $100 \mathrm{~mm}$ & 6 & Compressive strength \\
Cylinder $\Phi 100 \times \mathrm{L} 200 \mathrm{~mm}$ & 3 & Splitting Tensile Strength \\
Prism W100 $\times \mathrm{H} 100 \times \mathrm{L} 500 \mathrm{~mm}$ & 6 & Flexural Strength \\
Prism W $45 \times \mathrm{H} 20 \times \mathrm{L} 120 \mathrm{~mm}$ & 4 & Electrical Resistivity, Vibration, and Damping \\
\hline
\end{tabular}

\subsection{Compressive Strength}

The compressive strength tests (Figure 7) were carried out according to BS EN 12390-3 [40]. With a total of six cube samples per batch, previously removed from the tank and placed in an oven one day in advance in order to dry, three samples were tested after 7 days and the other half after 28 days. The results of the compressive tests are summarised in Figure 8.
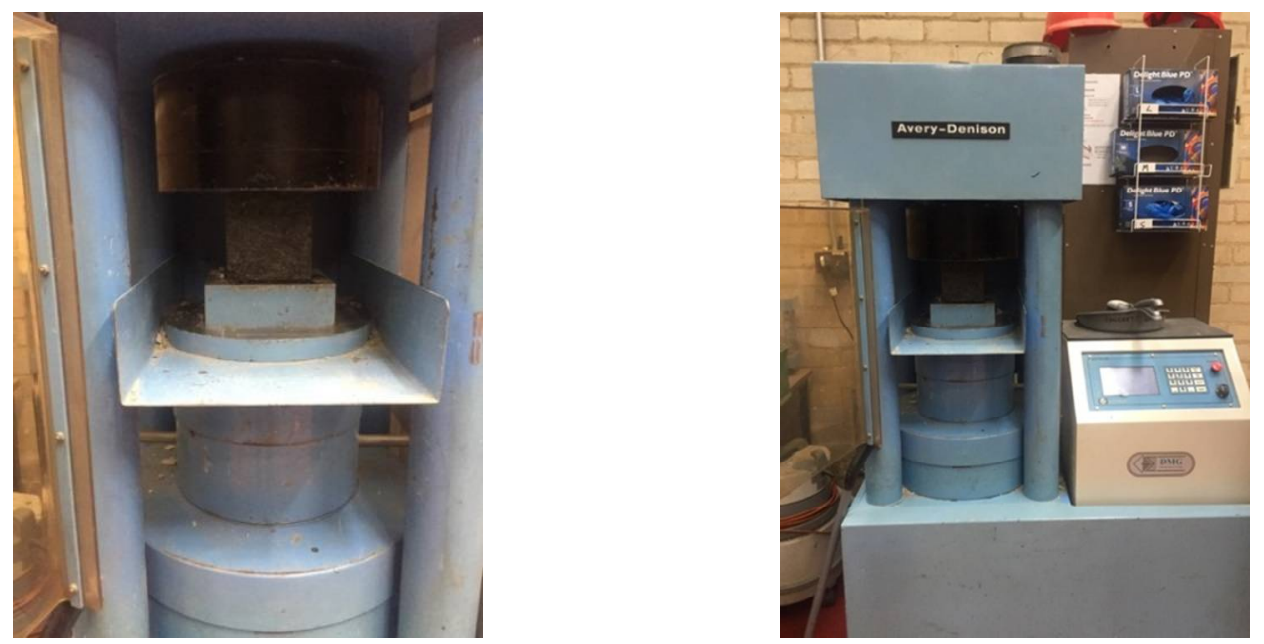

Figure 7. Compressive test setup. 


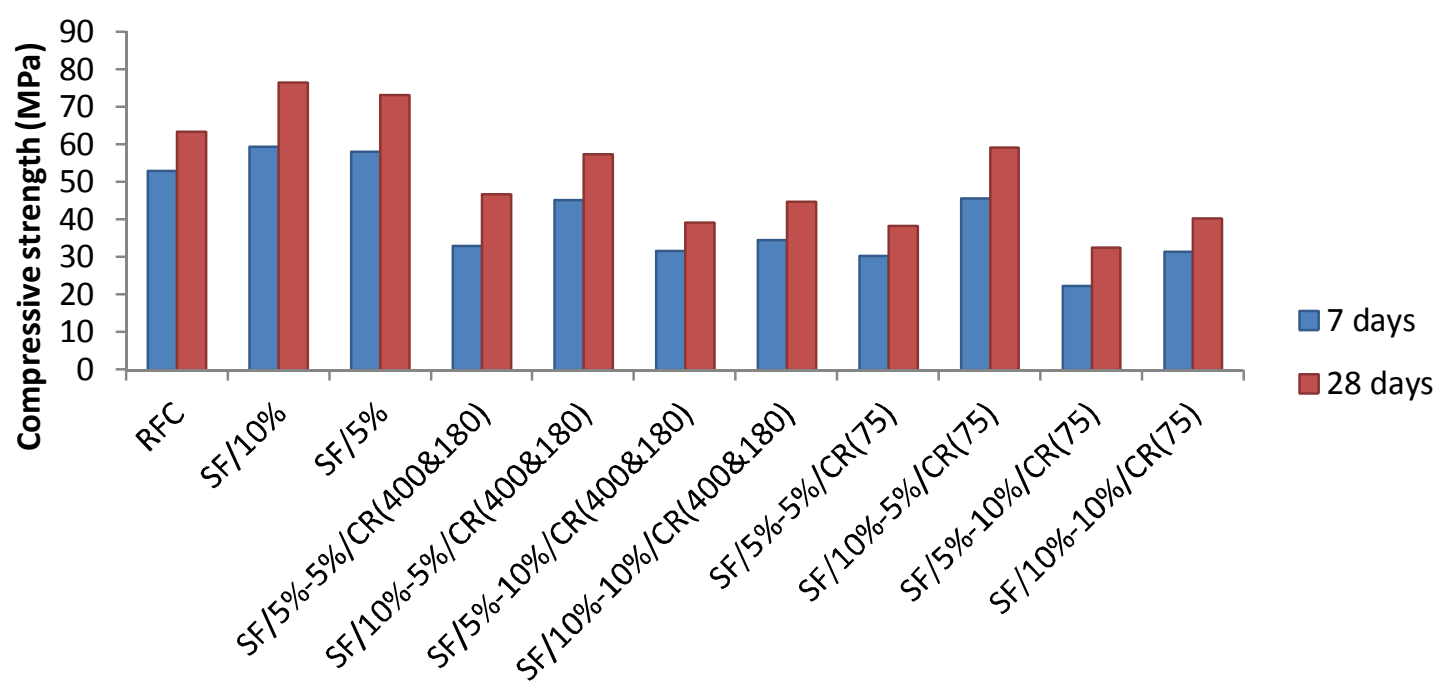

Figure 8. Compressive strength of crumb rubber concrete.

According to Figure 8, the results of compressive strength at 7 days and 28 days of experimental samples is shown. The reference concrete showed a compressive strength of $53.05 \mathrm{MPa}$ at 7 days and $63.33 \mathrm{MPa}$ at 28 days which shows good performance in compressive strength. The highest performance of compressive strength are the samples containing $5 \%$ and $10 \%$ silica fume, with 73.13 MPa and 76.5 MPa, respectively. Many previous literatures have indicated that the compressive strength would reduce in replacement of fine aggregate with crumb rubber. The results of this research also confirmed this phenomenon. In fact, all the samples with crumb rubber have less performance in compressive strength. There are only 2 samples containing crumb rubber that met the design requirements (55 MPa) according to BS EN 206-1 [37] in which they are 10\% silica fume/5\% 75 micro-crumb rubber and 10\% silica fume/5\% 400\&180 micro-crumb rubber. The best performance of compressive strength crumb rubber concrete sample is $10 \%$ silica fume $/ 5 \% 75$ micro-crumb rubber which has 59.2 MPa compressive strength at 28 days and it is only $6.5 \%$ lower than reference concrete.

The $10 \%$ silica fume or $5 \% 400 \& 180$ micro-crumb rubber has a similar result which is $57.3 \mathrm{MPa}$. Obviously, the addition of crumb rubber negatively affected the concrete performance while the silica fume improved it. This has been proved by different authors who establish a proportional relation between the increase of crumb rubber content in the concrete mixture and the reduction in its compressive strength [41-43]. However, the rubber concrete containing a proportion of $10 \%$ silica fume and $5 \%$ crumb rubber has shown considerable results by reaching $59.20 \mathrm{MPa}$ and $57.30 \mathrm{MPa}$ at 28 days in both cases: 75 micron and the mix of 180 and 400 micron, respectively. The fact that the addition of 75 micron crumb rubber results in higher concrete compressive strength comparing to the mix of 180 and 400 micron by approximately 3.3\% is due to the finer rubber particles that have a better ability in filling voids, thus offering a higher compressive strength [44]. Therefore, it has been deducted from the tests' results of this study that the crumb rubber concrete can be considered as a reliable material for railway concrete sleepers, since its compressive strength meet the standard for sleepers manufacturing ( $55 \mathrm{MPa})$.

\subsection{Splitting Tensile and Flexural Strengths}

According to BS EN 12390-6 [45], cylindrical specimens are used to test the rubber concrete splitting test after 28 days. In order to stabilize the specimens during the test, a pad is placed between the bearing surface and the press plate of the machine forming a corresponding strip loading between the top and the bottom of the specimens (Figure 9). At the beginning of the test, the loading was carried out continuously and uniformly at a speed ranging from 0.02 to $0.05 \mathrm{MPa} / \mathrm{s}$ until it reached $30 \mathrm{~N} / \mathrm{mm}^{2}$, the loading speed was then increased to range between 0.05 and $0.08 \mathrm{MPa} / \mathrm{s}$ until the end 
of the test. The test is stopped when the specimen is damaged and the damage load is recorded at an accuracy of $0.01 \mathrm{KN}$.

On the other hand, in order to measure the flexural strength of the rubberised concrete, several 4-point bending tests (Figure 10) have been carried out on prism specimens at 28 days according to BS EN 12390-5 [46]. The specimens are placed on two roller supports and loaded from an upper roller at a constant rate of $0.05 \mathrm{MPa} / \mathrm{s}$, and the tests' results stop recording once the specimens fail. The results of both tests are presented in each graph of Figure 11.

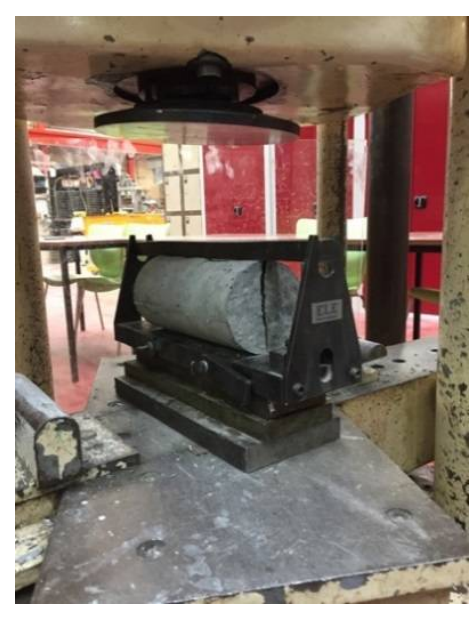

Figure 9. Splitting tensile test.

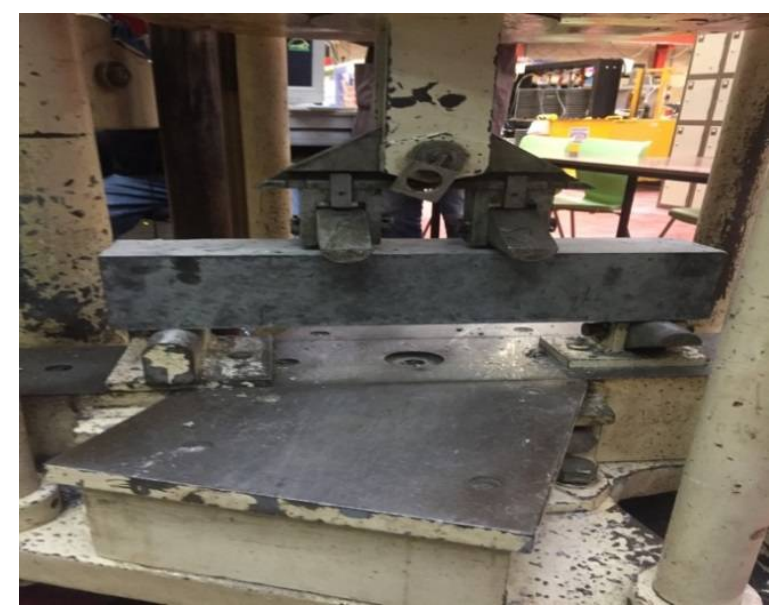

Figure 10. 4-point bending test.

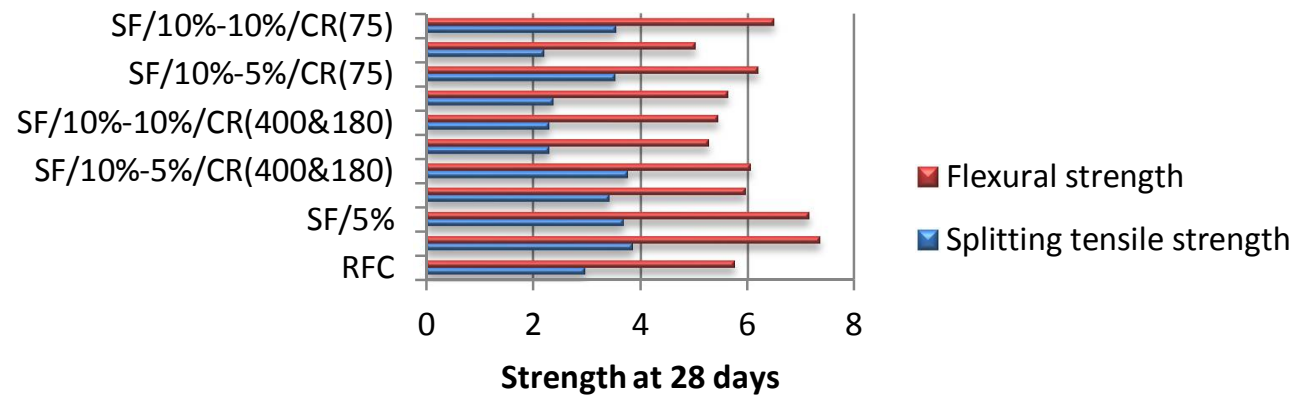

Figure 11. Splitting tensile strength of crumb rubber concrete. 
According to BS EN 12390-6 [45], the splitting tensile strength of concrete at 28 days was calculated using the function below:

$$
f_{c t}=\frac{2 F}{\pi L D}
$$

where $f_{c t}$ is the splitting tensile strength (MPa), $\mathcal{E}$ is the maximum load $(\mathrm{N}), L$ is the length of the line of contact of the specimen ( $\mathrm{mm}$ ), and $D$ is the designated cross-sectional dimension ( $\mathrm{mm}$ ).

Similarly to the compressive strength results, the increase in silica fume content clearly improved the splitting tensile strength by $30 \%$ comparing to conventional concrete, reaching a maximum value of $3.85 \mathrm{MPa}$ at 28 days as shown in Figure 11. Also, as expected from previous studies, the rubber powder replacing fine aggregates has considerably decreased the splitting tensile strength, especially when its amount is increased to $10 \%$ and mixed with $5 \%$ silica fume, leading to a minimum value lower than the one obtained from the conventional concrete by $35 \%$ in the case of 75 micro rubber, and $30 \%$ in the case of mixing 180 and 400 micro rubber. Though, the proportions that seemed to show better performance than normal concrete are the ones containing $10 \%$ silica fume: mixed with $5 \%$ crumb rubber in the case of 180 and 400 micro rubber, and 10\% in the case of 75 micro rubber (3.75 MPa and 3.54 MPa respectively).

Likewise, the flexural strength has been calculated following the British standard BS EN 12390-5 [46]:

$$
f_{c f}=\frac{F I}{d_{1} d_{2}^{2}}
$$

where $f_{c f}$ is the flexural strength (MPa), $F$ is the maximum load $(\mathrm{N}), I$ is the length between roller supports (mm), and $d_{1}$ and $d_{2}$ are the cross-sectional dimensions of specimen (mm).

As shown in Figure 11, similar trend was observed between the splitting tensile and the flexural strengths. The maximum value recorded is $7.34 \mathrm{MPa}$ and the minimum is $5.02 \mathrm{MPa}$, both correspond to $\mathrm{SF} 10 \% / \mathrm{CR} 0 \%$ and SF5\%/CR10\%, respectively. Same observations have been deducted in the flexural test, which are the improvement of concrete strength by increasing the silica fume content and decreasing the crumb rubber proportion, and its deterioration in the opposite way. Many previous studies have come to similar conclusions regarding both, splitting tensile and flexural strengths of rubberised concrete, when replacing normal coarse aggregates with recycled rubber crumb [21,47,48]. Yet, the specimens containing a combination of $10 \%$ silica fume and whether $5 \%$ of the $180 \& 400$ micro rubber or $10 \%$ of 75 micro rubber have shown acceptable flexural strengths superior to plain concrete by $8 \%$ and $13 \%: 6.19 \mathrm{MPa}$ and $6.49 \mathrm{MPa}$, respectively.

The tensile and flexural ratio can be calculated by:

$$
\begin{aligned}
& \text { tensile ratio }=\frac{f_{t}^{\prime}}{f_{c}^{\prime}} * 100 \% \\
& \text { tensile ratio }=\frac{f_{f}^{\prime}}{f_{c}^{\prime}} * 100 \%
\end{aligned}
$$

The tensile ratio and flexural ratio have been calculated by Formulas (3) and (4) shown in Figure 12. Both the tensile and flexural ratio follow the same trend as flexural/splitting tensile strength. From the graph, all the flexural ratio of crumb rubber concrete are more than $10 \%$. The highest tensile/flexural ratio is $10 \%$ silica fume $/ 10 \% 75$ micro rubber, which are $8.78 \%$ and $16.10 \%$, respectively. Non-crumb rubber samples show very low tensile ratio, they are: $4.69 \%$ for reference concrete, $5.03 \%$ for $5 \%$ silica fume concrete and $5.03 \%$ for 10\% silica fume; $10 \%$ silica fume $/ 10 \% 400 \& 180$ micro-crumb rubber has similar tensile ratio with non-crumb rubber sample, which is $5.11 \%$. 


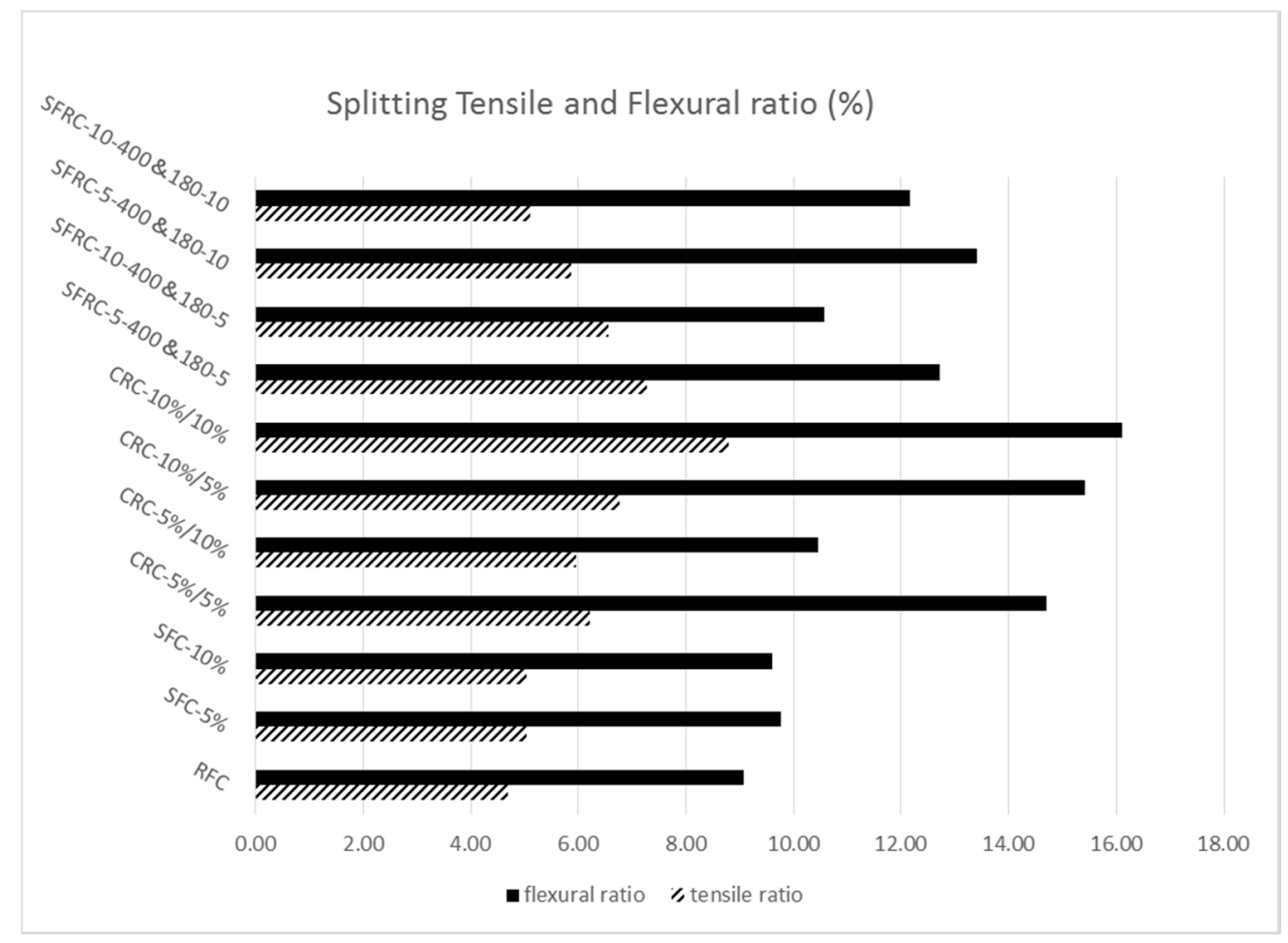

Figure 12. Splitting tensile and flexural ratio of crumb rubber concrete.

\subsection{Electrical Resistivity}

Generally, there are two main methods to measure the electrical resistance of cementitious materials: two-electrode method and four-electrode method [49]. In this study, the two-electrode method has been considered to test prism specimens at 28 days, after having been removed from the tank for natural drying prior for testing. Victor VC60B+, an insulation tester, has been used to determine the electrical resistance (ohm) of the specimens, by connecting leads to both their ends and setting the voltage at a constant value of 1000 Volts as shown in Figure 13. The results of the experiments, shown in Figure 12, are recorded $60 \mathrm{~s}$ later.

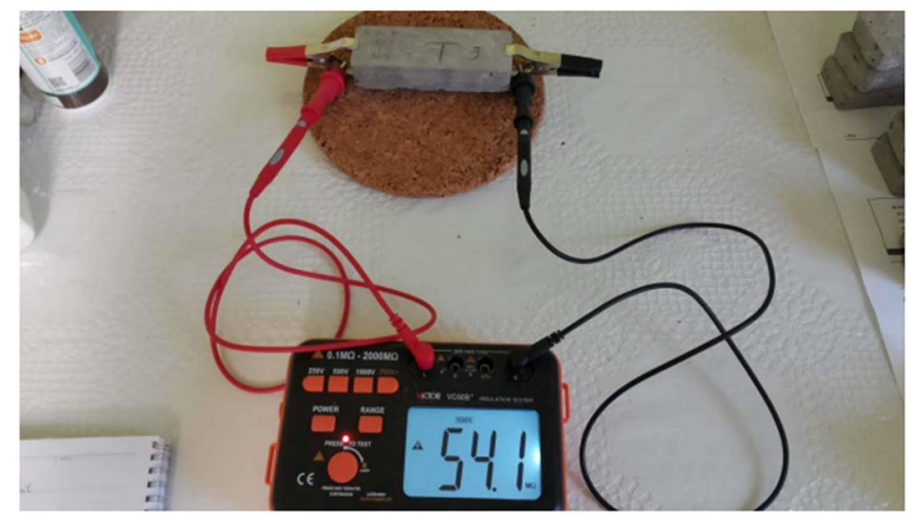

Figure 13. Electrical resistivity test.

After 28 days, the electrical resistance was measured then calculated using the resistance equation [22]:

$$
\rho=k * R ; k=\frac{A}{L}
$$


where $R$ is the resistance of concrete, $k$ is a geometrical factor which depends on the size and shape of the specimen, $A$ is the cross-sectional area perpendicular to the current, $L$ is the height of the specimen.

As it can be seen from Figure 14, the plain concrete specimen has the lowest electrical resistivity among all others: $255 \mathrm{k} \Omega$. The concrete's electrical resistivity increased once the silica fume has been added, which proved what has been found by other researchers [23,50,51]. Obviously, as the rubber is considered as a good insulator, the concrete samples containing crumb rubber have shown the best results in terms of electrical resistivity: $374.25 \mathrm{k} \Omega$ and $371 \mathrm{k} \Omega$ for SF10\%/CR10\% (180 \& 400) and $\mathrm{SF} 10 \% / \mathrm{CR} 5 \%$ (75) respectively. Therefore, the addition of crumb rubber is capable of enhancing the electrical resistivity of plain concrete by $47 \%$, and by $17 \%$ if it contained $10 \%$ of silica fume. In fact, both insulator materials (silica fume and rubber) have shown good performance as expected, due to their ability to prevent the two electrodes to transmit current in concrete [52].

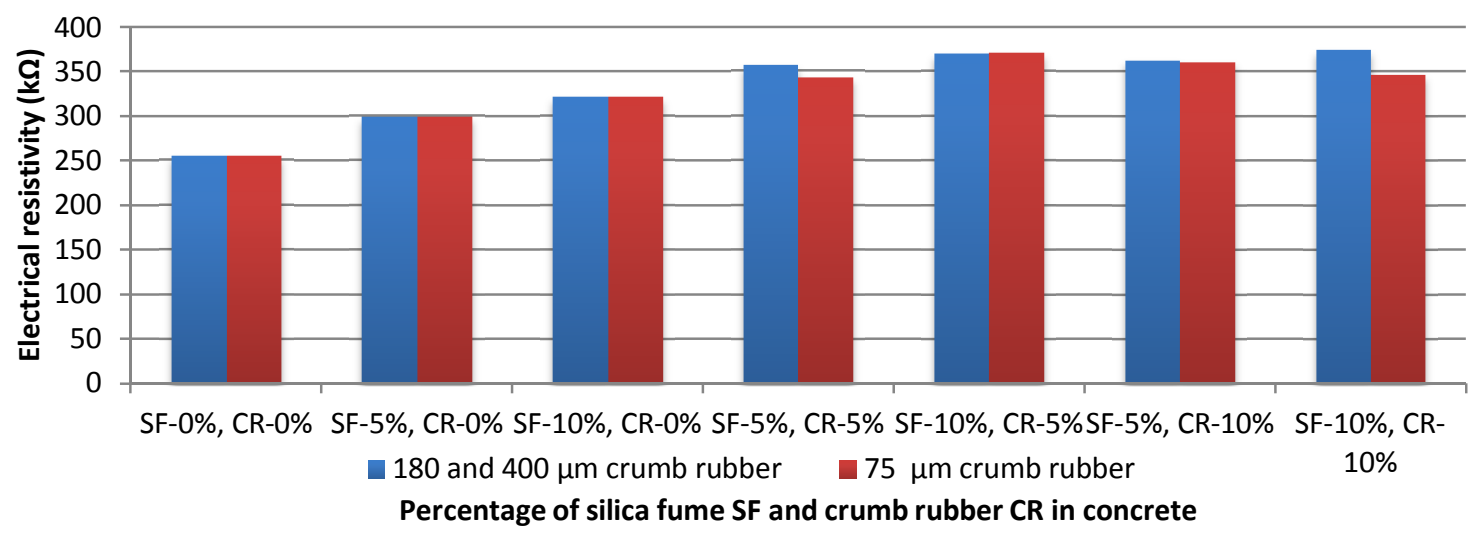

Figure 14. Electrical resistivity of rubber concrete with different particles size.

\subsection{Vibration Damping}

The vibration tests have been conducted in the civil engineering laboratory to avoid vibration from surrounding environment. Prism specimens were used to carry out these experiments using the following equipment: computer with PROSIG hammer system, DATS modal analysis software, and an accelerometer. The specimens' surfaces have been cleaned to eliminate bias in tests results [52,53], and a stable support (Figure 15) was used to fix the samples as a cantilever beam since placing the stationary platform on the concrete floor makes the resonant frequency relatively high. The vibration of samples was excited by a PCB hammer (Figure 16) at a frequency range of 0 to $1600 \mathrm{~Hz}$ [54,55], and as shown in Figure 16, a 5-order average vibration response of each sample is presented by the frequency response function (FRF). The graph of time series is illustrated in Figure 17.

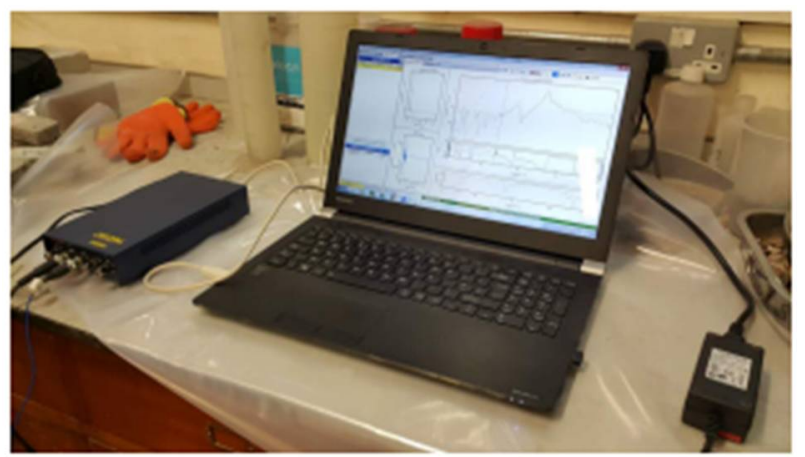

Figure 15. DATS modal analysis suite. 


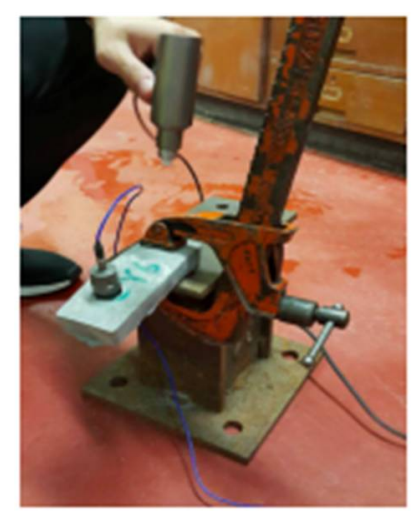

Figure 16. Damping test.

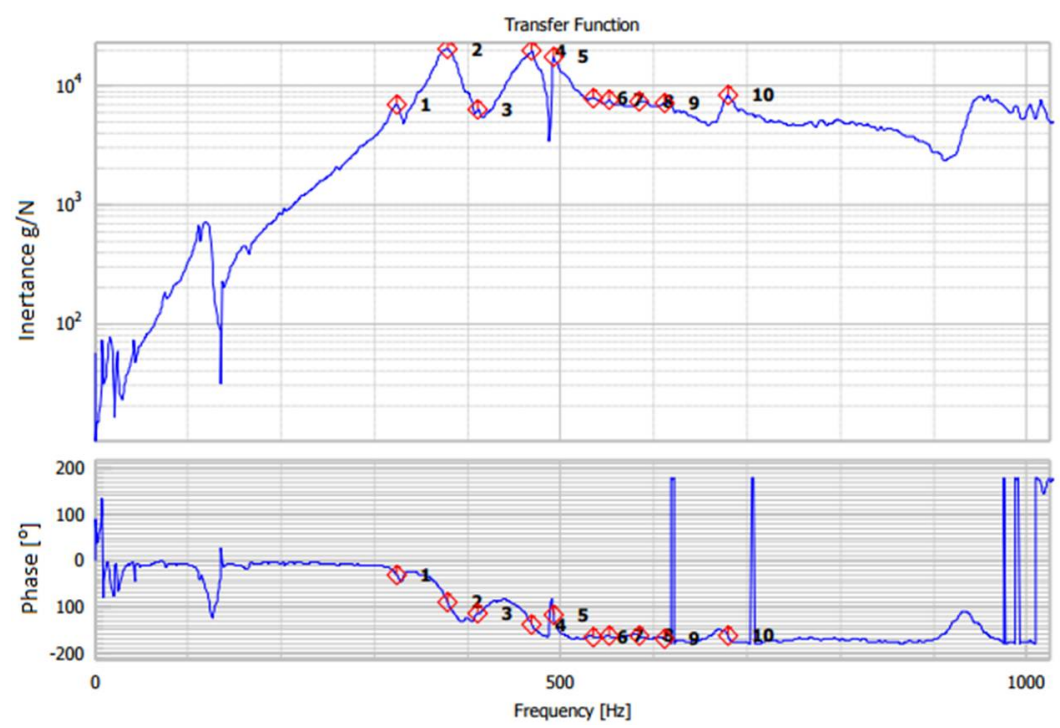

Figure 17. Frequency response function.

Generally, there are two methods to analyse the damping ratio and both have been considered in this study. The first method is called exponential curve fitting method (ECFM); this method is based on calculating the damping ratio directly using the natural frequency and the vibration response of the concrete samples from the FRF graph, as can be seen from Figure 17. The specimen containing $10 \%$ silica fume has a natural frequency of $469 \mathrm{~Hz}$, and the one containing the same proportion of silica fume in addition to $5 \%$ of crumb rubber $(75$ micron) has $500 \mathrm{~Hz}$ of natural frequency. All the natural frequencies recorded during the tests are presented in Table 5, although, factors such as the high stiffness of concrete and thickness of the metal gasket can affect the range of the natural frequencies $[52,56]$. 
Table 5. Types of moulds and corresponding tests.

\begin{tabular}{ccccccc}
\hline \multirow{2}{*}{ No. } & \multirow{2}{*}{ Mixes } & \multicolumn{3}{c}{ Natural Frequency (Hz) } & \multirow{2}{*}{ S.D. } \\
\cline { 3 - 6 } & & Sample 1 & Sample 2 & Sample 3 & Average & \\
\hline 1 & $\mathrm{RFC}$ & 478 & 451 & 486 & 471.67 & \pm 18.34 \\
2 & $\mathrm{SF} / 10 \%$ & 469 & 427 & 433 & 443 & \pm 22.716 \\
3 & $\mathrm{SF} / 5 \%$ & 457 & 437 & 462 & 452 & \pm 13.23 \\
4 & $\mathrm{SF} / 5 \%-5 \% / \mathrm{CR}(400 \& 180)$ & 476 & 452 & 463 & 463.67 & \pm 12.01 \\
5 & $\mathrm{SF} / 10 \%-5 \% / \mathrm{CR}(400 \& 180)$ & 456 & 439 & 454 & 449.67 & \pm 9.29 \\
6 & $\mathrm{SF} / 5 \%-10 \% / \mathrm{CR}(400 \& 180)$ & 479 & 493 & 474 & 482 & \pm 9.85 \\
7 & $\mathrm{SF} / 10 \%-10 \% / \mathrm{CR}(400 \& 180)$ & 441 & 446 & 435 & 440.67 & \pm 5.51 \\
8 & $\mathrm{SF} / 5 \%-5 \% / \mathrm{CR}(75)$ & 443 & 462 & 431 & 445 & \pm 15.63 \\
9 & $\mathrm{SF} / 10 \%-5 \% / \mathrm{CR}(75)$ & 477 & 500 & 459 & 477 & \pm 20.55 \\
10 & $\mathrm{SF} / 5 \%-10 \% / \mathrm{CR}(75)$ & 453 & 456 & 472 & 460 & \pm 10.21 \\
11 & $\mathrm{SF} / 10 \%-10 \% / \mathrm{CR}(75)$ & 488 & 493 & 512 & 498 & \pm 12.66 \\
\hline
\end{tabular}

The acceleration-time graph is then plotted and the exponential line is fitted with the peak amplitude according to the decreasing trend of the vibration response, while the equation of the exponential line is generated from the Microsoft Excel program as illustrated in Figure 18.

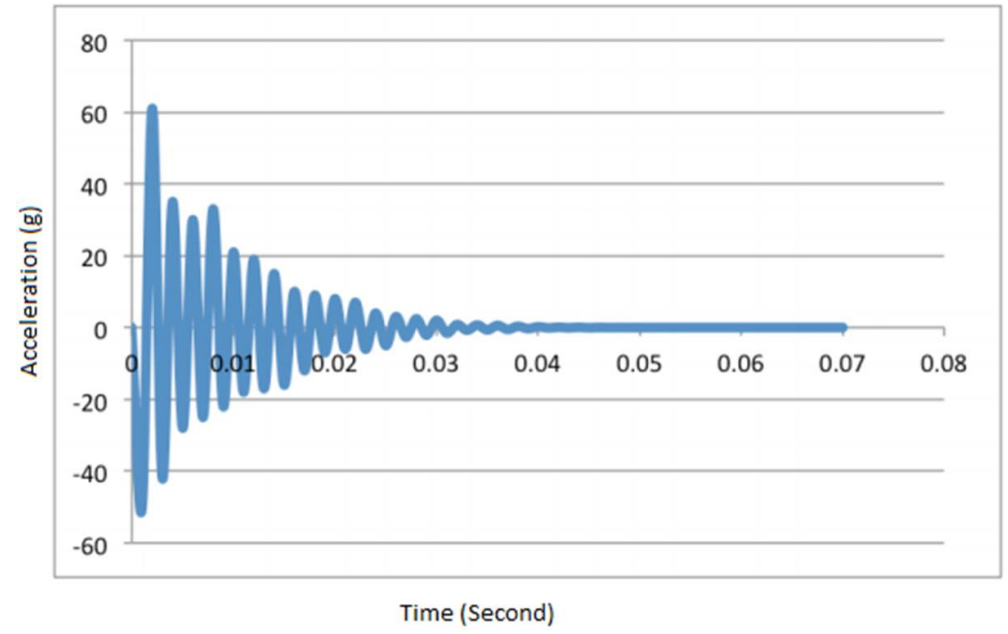

Figure 18. Vibration response of the concrete.

Finally, the equation obtained from the vibration graph (Figure 19) is compared with the reduced general mathematical equation representing the amplitude (Equation (4)), and the damping ratio is obtained as follows:

$$
A_{t}=A_{0} \cdot e^{-\zeta \cdot w_{n} \cdot t}
$$

where $A_{t}$ is the amplitude, $A_{0}$ is the peak amplitude, $\zeta$ is the damping ratio, $w_{n}$ is the natural frequency (rad/s) equal to $2 \pi f_{n}$ where $f_{n}$ is the natural frequency in $\mathrm{Hz}$, and $\mathrm{t}$ is the time in seconds. The calculation of the damping ratio of the SF5\%-CR10\% sample presented by the graph of Figure 19 has led to 0.0324 , which is $3.24 \%$ of critical damping ratio.

The second method is used to verify the value obtained from the ECFM and in order to make sure that the tests' results are more reliable. It is called the logarithmic decrement method (LDM), and the damping ratio in this case is calculated using the logarithmic decrement formulas (Equations (5) and (6)):

$$
\begin{gathered}
\delta=\frac{1}{n} \ln \frac{A_{0}}{A_{n}} \text { if } n=1,2,3 \ldots \\
\zeta=\frac{1}{\sqrt{1+\left(\frac{2 \pi}{\delta}\right)^{2}}} \approx \frac{\delta}{2 \pi}
\end{gathered}
$$


where $\delta$ is the damping index, $A_{0}$ is the peak amplitude, $A_{n}$ is the amplitude after $n$ number of cycles, and $\zeta$ is the damping ratio.

The damping ratio estimated from the LDM for the same sample tested before using the ECFM is $0.0323(3.23 \%)$, which presents a small error of $0.31 \%$. The results regarding all the samples are plotted in the graph of Figure 20. The graph shows that the two methods have similar trend. The reference concrete has the lowest damping ratio with 0.02239 and 0.02098 respectively according to the ECFM and LDM methods. The addition of $10 \%$ silica fume improved slightly the concrete's damping ratio to reach 0.02822 using ECFM and 0.2791 using LDM, and a little more improvement of 19 and $21 \%$ respectively when $10 \%$ of 75 micron rubber has been added. This improvement is due to the large interface area between the cement matrix and silica fume particles which offer better vibration energy dissipation $[57,58]$. Finally, the 180\&400 micron rubber have proved to have the best effect on the damping ratio of concrete, by reaching the maximum values obtained in this test: 0.04499 using ECFM and 0.04451 using LDM, which present an improvement of 100 and $112 \%$ respectively comparing to the conventional concrete. These results confirm the theory stating that the damping ratio of concrete improves with the increase in the size and the amount of rubber content as declared by Zheng at al. [52]. A damping ratio of $3 \%$ could easily reduce up to $20-30 \%$ of dynamic actions (bending, shear, and force); however, in order to suppress large-amplitude vibrations the damping coefficient should be around $4-5 \%$ [57]. Consequently, since the static and dynamic properties of the rubberised concrete (180\&400 micron) meet the design standards, it should highly be recommended for concrete railway sleepers' manufacturing [53,57].

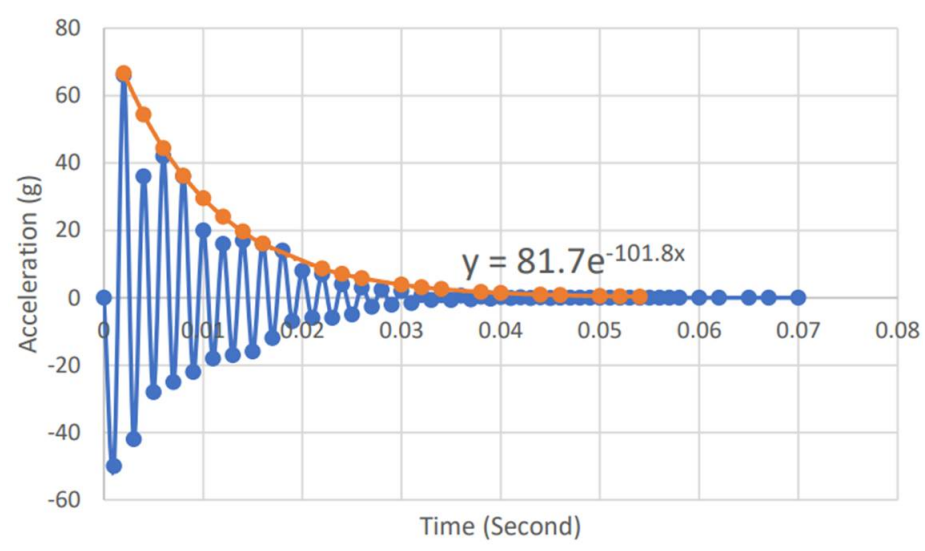

Figure 19. Curve fitting of vibration response of the concrete ( $75 \mu \mathrm{m}$ crumb rubber).

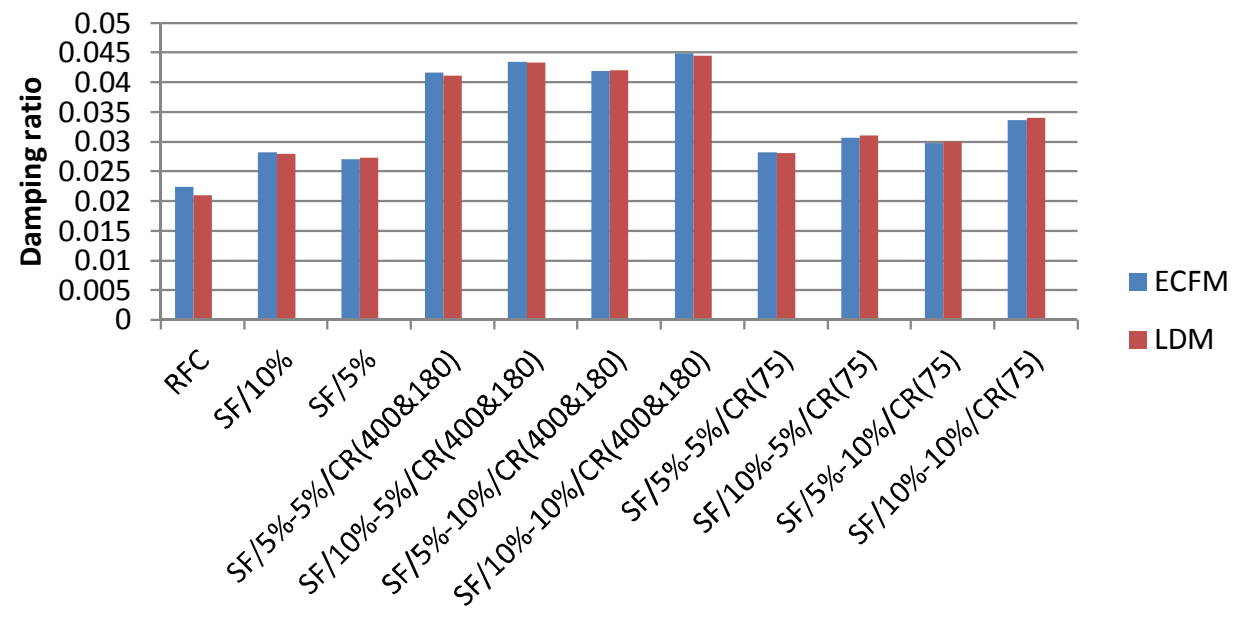

Figure 20. Dynamic damping of crumb rubber concrete at 28 days. 


\subsection{Dynamic Flexural Moduli}

According to Kaewunruen et al., the dynamic flexural modulus of elasticity demonstrates the elastic behaviour of material under flexural loading. The dynamic flexural modulus can be estimated from Equation (9) [49,59-61]. Figure 21 reveals that the early age dynamic moduli at 7 days of the rubberized concrete are decreased compared to the reference concrete (from $7 \%$ to $28 \%$, depending on the mixes). This implies that the release of prestressing force on concrete sleepers should be gentle to minimise the effect on initial deformations (i.e., pre-camber and elastic shortening). Figure 22 shows the dynamic moduli of the concrete at 28 days. It can be observed that the use of silica fume can increase the dynamic moduli at 28 days. The deviation of dynamic moduli of the rubberized concrete is from $5 \%$ to $26 \%$ compared to the reference concrete. Comparatively, it is found that, at 28 days, the dynamic flexural behavior could be expected to be similar to traditional high-strength concrete (reference). This implies that the difference in creep and shrinkage would be minimal to normal concrete sleepers. These requirements are critical for concrete sleepers in ballasted railway tracks. However, the application of this rubberised concrete can be applied to concrete slabs in ballastless tracks of which its requirement is slightly less stringent [59-63].

$$
E_{d}=0.021 \rho^{1.5} \sqrt{f_{c}}
$$

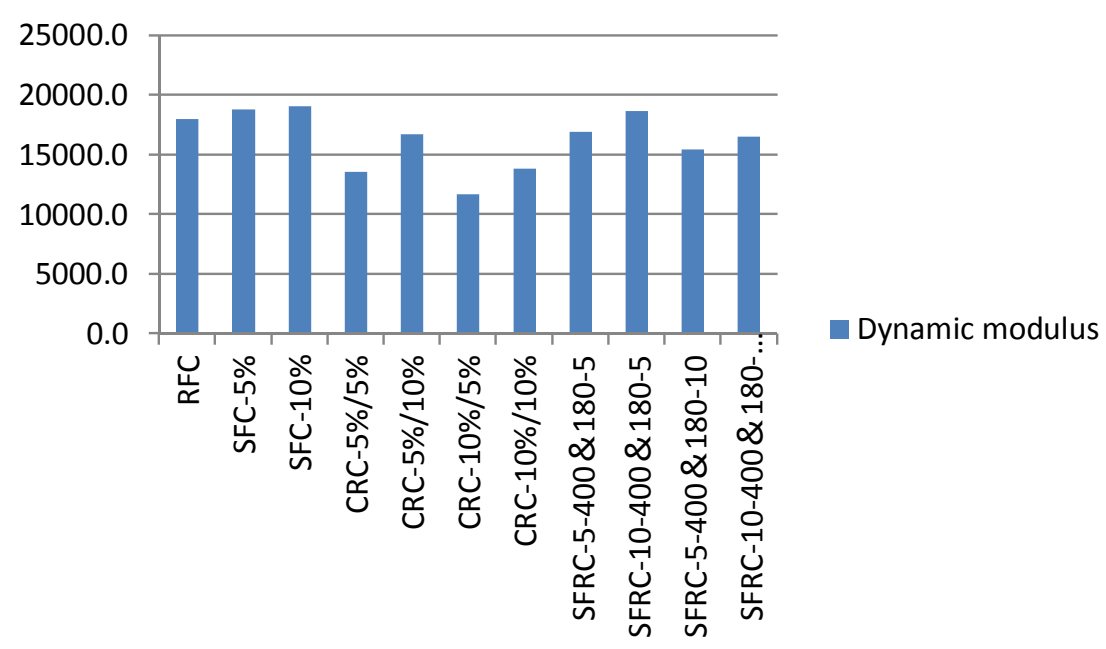

Figure 21. Early-age dynamic moduli of crumb rubber concrete at 7 days (MPa).

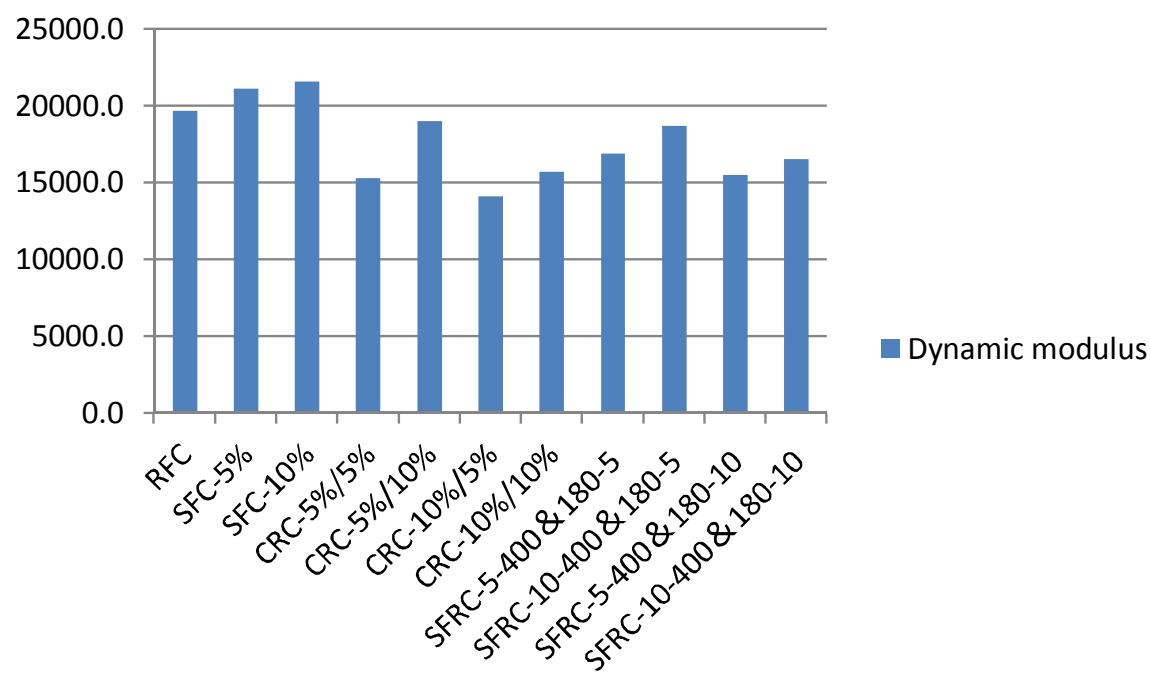

Figure 22. Dynamic moduli of crumb rubber concrete at 28 days (MPa). 


\section{Conclusions}

Railway traffic environment is aggressive and the railway infrastructure has to experience heavy-haul or high-speed rail operation. Therefore, material for railway infrastructure needs to be strong, durable, resilient and tough to withstand various unexpected damage. Waste tyre is a global environmental problem which is non-biodegradability, flammability and chemical composition. Waste tyre cannot be solved as a normal method like disposal. This research study aimed to develop an environmentally friendly concrete using crumb rubber, recycled form waste rubber tyres (75 micron and 180 micro mixed with 400 micron), as micro-filler to make concrete sleepers that meet with the railway requirements. Although the emphasis is placed on concrete sleepers in ballasted railway tracks, the application of this recycled concrete can also be applied to concrete slabs in ballastless tracks. Based on diverse proportions of crumb rubber and silica fume, eleven different types of concrete were casted according to British standard. The first experiments carried out on the concrete specimens tested their compressive strength at 7 and 28 days, as it presents the most important property of this material. Similar to previous studies' findings, it has been deducted that the increase in the rubber content results in a drop in compressive strength. However, the rubber concrete containing a proportion of $10 \%$ silica fume and $5 \%$ crumb rubber has shown considerable results by reaching 57.30 MPa and 59.20 MPa at 28 days in both rubber particle cases 75 micro and the mix of 180 and 400 micro respectively, thus meeting the standard for railway sleepers manufacturing ( $55 \mathrm{MPa})$. Likewise, it has been observed a significant deterioration in both splitting tensile and flexural strengths when increasing the crumb rubber proportion in concrete. Still, the proportions that seemed to show better splitting tensile performance than plain concrete are the ones containing $10 \%$ silica fume: mixed with $5 \%$ crumb rubber in the case of 180 and 400 micro rubber, and $10 \%$ in the case of 75 micro rubber (3.75 MPa and 3.54 MPa respectively).

On the other hand, the specimens containing a combination of $10 \%$ silica fume and whether $5 \%$ of the $180 \& 400$ micro rubber or $10 \% 75$ micro rubbers have shown acceptable flexural strengths superior to plain concrete by 8 and 13\%: 6.19 MPa and 6.49 MPa, respectively. In terms of electrical resistivity, the concrete samples containing crumb rubber have shown the best results: $374.25 \mathrm{k} \Omega$ and $371 \mathrm{k} \Omega$ for SF10\%/CR10\% (180\&400) and SF10\%/CR5\% (75) respectively. Therefore, the addition of crumb rubber is capable of enhancing the electrical resistivity of conventional concrete up to $47 \%$. Finally, by conducting vibration tests on rubberised concrete and using both the exponential curve fitting method (ECFM) and the logarithmic decrement method (LDM), it has been concluded that the crumb rubber has clearly improved the concrete's damping ratio, especially when using the $180 \& 400$ micro which resulted in an improvement of $100 \%$ comparing to normal concrete. It is therefore recommended from the results of this study to use crumb rubber in concrete as micro-filler, and more precisely the $\mathrm{SF} / 10 \%-\mathrm{CR} / 5 \%(400 \& 180)$ as it showed the best performance in all tests and meets the requirements of railway concrete sleepers. From the environmental perspective, the use of crumb rubber in concrete presents one of the best alternatives while dealing with rubber waste, as it will help both the environment protection and also the reduction in railway sleepers cost.

Author Contributions: Conceptualization, S.K., Y.C. and Z.X.; Methodology, S.K., Y.C. and Z.X.; Validation, D.L., Y.C. and Z.X.; Formal Analysis, D.L.; Investigation, Y.C. and Z.X.; Resources, S.K.; Writing-Original Draft Preparation, D.L., Y.C., Z.X.; Writing-Review \& Editing, S.K.; Visualization, D.L.; Supervision, S.K.; Funding Acquisition, S.K.

Funding: This research was funded by the Japan Society for Promotion of Science (JSPS) grant number L15701 and the APC was funded by the European Commission for H2020-MSCA-RISE Project No. 691135 "RISEN: Rail Infrastructure Systems Engineering Network".

Acknowledgments: The first author wishes to gratefully acknowledge the Japan Society for Promotion of Science (JSPS) for his JSPS Invitation Research Fellowship (Long-term), Grant No. L15701, at Track Dynamics Laboratory, Railway Technical Research Institute and at Concrete Laboratory, the University of Tokyo, Tokyo, Japan. The JSPS financially supports this work as part of the research project entitled "Smart and reliable railway infrastructure". The authors are very grateful to the European Commission for H2020-MSCA-RISE Project No. 691135 “RISEN: Rail Infrastructure Systems Engineering Network" (www.risen2rail.eu) [64]. In addition, the sponsorships and 
assistance from CEMEX, Network Rail, Lehigh Technologies Inc., and RSSB (Rail Safety and Standard Board, UK) are highly appreciated.

Conflicts of Interest: The authors declare no conflict of interest.

\section{References}

1. Gourley, J.T.; Johnson, G.B. Developments in geopolymer precast concrete. In Proceedings of the Geopolymer 2005 World Congress, Geopolymer Green Chemistry and Sustainable Development Solutions, Saint-Quentin, France, 29 June-1 July 2005; pp. 139-143.

2. Kaewunruen, S.; You, R.; Ishida, M. Composites for Timber-Replacement Bearers in Railway Switches and Crossings. Infrastructures 2017, 2, 13. [CrossRef]

3. Kaewunruen, S.; Wu, L.; Goto, K.; Najih, Y.M. Vulnerability of Structural Concrete to Extreme Climate Variances. Climate 2018, 6, 40. [CrossRef]

4. FIP Commission on Prefabrication, FIP Commission on Prefabrication; Working Group on Concrete Railway Sleepers \& Fédération Internationale de la Précontrainte. Working Group on Concrete Railway Sleepers. Concrete Railway Sleepers; Thomas Telford Services Ltd.: London, UK, 1987.

5. Gupta, T.; Chaudhary, S.; Sharma, R.K. Mechanical and durability properties of waste rubber fiber concrete with and without silica fume. J. Clean. Prod. 2016, 112, 702-711. [CrossRef]

6. Aiello, M.; Leuzzi, F. Waste tyre rubberized concrete: Properties at fresh and hardened state. Waste Manag. 2010, 30, 1696-1704. [CrossRef] [PubMed]

7. Thomas, B.S.; Gupta, R.C. A comprehensive review on the applications of waste tire rubber in cement concrete. Renew. Sustain. Energy Rev. 2016, 54, 1323-1333. [CrossRef]

8. Remennikov, A.M.; Kaewunruen, S. A review of loading conditions for railway track structures due to train and track vertical interaction. Struct. Control Health Monit. 2008, 15, 207-234. [CrossRef]

9. Silva, É.A.; Pokropski, D.; You, R.; Kaewunruen, S. Comparison of structural design methods for railway composites andplastic sleepers and bearers. Aust. J. Struct. Eng. 2017, 18, 160-177. [CrossRef]

10. Kaewunruen, S.; Remennikov, A.M. Progressive failure of prestressed concrete sleepers under multiple high-intensity impact loads. Eng. Struct. 2009, 31, 2460-2473. [CrossRef]

11. Cai, H.Q. Structure analysis of railway. J. Hebei Inst. Arch. 2006, 29, 18-20.

12. Kaewunruen, S.; Remennikov, A.M. Influence of voids and pockets on the vibration characteristics of prestressed concrete sleepers. In Proceedings of the Society of Experimental Mechanics (SEM) Annual Conference and Exhibition, Orlando, FL, USA, 19-22 February 2007; pp. 3-6.

13. Esveld, C. Modern Railway Track, 2nd ed.; MRT-Productions: Delft, The Netherlands, 2001; ISBN 90-800324-3-3.

14. Indraratna, B.; Rujikiatkamjorn, C.; Salim, W. Advanced Rail Geotechnology-Ballasted Track; CRC Press: London, UK, 2011.

15. Remennikov, A.M.; Kaewunruen, S. Resistance of railway concrete sleepers to impact loading. In Proceedings of the 7th International Conference on Shock \& Impact Loads on Structures, Beijing, China, 17-19 October 2007; pp. 489-496.

16. You, R.; Li, D.; Ngamkhanong, C.; Janeliukstis, R.; Kaewunruen, S. Fatigue Life Assessment Method for Prestressed Concrete Sleepers. Front. Built Environ. 2017, 3, 68. [CrossRef]

17. Zhang, X.; Thompson, D.J.; Squicciarini, G. Sound radiation from railway sleepers. J. Sound Vib. 2016, 369, 178-194. [CrossRef]

18. Hameed, A.S.; Shashikala, A. Suitability of rubber concrete for railway sleepers. Perspect. Sci. 2016, 8, 32-35. [CrossRef]

19. Salam, H.E.; Sherbini, A.S.; Seleem, M.H.; Balaha, M.M. Impact Resistance of Rubberized Concrete. Eng. Res. J. 2008, 31, 265-271.

20. Topçu, İ.B.; Demir, A. Durability of Rubberized Mortar and Concrete. J. Mater. Civ. Eng. 2007, 19, $173-178$. [CrossRef]

21. Topçu, İ.B.; Şengel, S. Properties of concretes produced with waste concrete aggregate. Cem. Concr. Res. 2004, 34, 1307-1312. [CrossRef]

22. Anagennisi Project. Rubberised Concrete. 2017. Available online: http://anagennisi.org/wordpress/ portfolio/rubberised-concrete-optimised-mix (accessed on 14 February 2018). 
23. Sol-Sánchez, M.; Thom, N.; Moreno-Navarro, F.; Rubio-Gámez, M.; Airey, G. A study into the use of crumb rubber in railway ballast. Constr. Build. Mater. 2015, 75, 19-24. [CrossRef]

24. Toutanji, $\mathrm{H}$. The use of rubber tire particles in concrete to replace mineral aggregates. Cem. Concr. Compos. 1996, 18, 135-139. [CrossRef]

25. Khaloo, A.R.; Dehestani, M.; Rahmatabadi, P. Mechanical properties of concrete containing a high volume of tire-rubber particles. Waste Manag. 2008, 28, 2472-2482. [CrossRef] [PubMed]

26. Ganjian, E.; Khorami, M.; Maghsoudi, A.A. Scrap-tyre-rubber replacement for aggregate and filler in concrete. Constr. Build. Mater. 2009, 23, 1828-1836. [CrossRef]

27. Paine, K.A.; Dhir, R.K.; Moroney, R.; Kopasakis, K. Use of Crumb Rubber to Achieve Freeze/Thaw Resisting Concrete. In Proceedings of the International Conference on Concrete for Extreme Conditions, Dundee, UK, 9-11 September 2002; pp. 485-498. [CrossRef]

28. Hernández-Olivares, F.; Barluenga, G. Fire performance of recycled rubber-filled high-strength concrete. Cem. Concr. Res. 2004, 34, 109-117. [CrossRef]

29. Fattuhi, N.; Clark, L. Cement-based materials containing shredded scrap truck tyre rubber. Constr. Build. Mater. 1996, 10, 229-236. [CrossRef]

30. Van Dyk, B.J.; Edwards, J.R.; Dersch, M.S.; Ruppert, C.J., Jr.; Barkan, C.P.L. Evaluation of dynamic and impact wheel load factors and their application in design processes. Proc. Inst. Mech. Eng. Part F 2017, 231, $33-43$. [CrossRef]

31. Kaewunruen, S.; Remennikov, A.M. Sensitivity analysis of free vibration characteristics of an in situ railway concrete sleeper to variations of rail pad parameters. J. Sound Vib. 2006, 298, 453-461. [CrossRef]

32. BS EN 13230 Concrete Sleepers and Bearers; British Standards Institute: London, UK, 2016.

33. BS EN 934-2 Admixtures for Concrete, Mortar and Grout; British Standards Institute: London, UK, 2009.

34. Mazloom, M.; Ramezanianpour, A.; Brooks, J. Effect of silica fume on mechanical properties of high-strength concrete. Cem. Concr. Compos. 2004, 26, 347-357. [CrossRef]

35. Elkem-Microsilica Grade 940 for Construction. 2017. Available online: https://www.elkem.com/siliconmaterials/high-performance-concrete/microsilica-concrete-grades/microsilica-grade-940-construction/ (accessed on 14 February 2018).

36. BS EN 12620 Aggregates for Concrete; British Standards Institute: London, UK, 2013.

37. BS EN 206-1 Concrete: Part 1-Specification, Performance, Production and Conformity; British Standards Institute: London, UK, 2000.

38. Mirza, O.; Kaewunruen, S. Influence of shear bolt connections on modular precast steel-concrete composites for track support structures. Steel Comp. Struct. 2018, 27, 647-659.

39. BS EN 13139 Aggregates for Mortar; British Standards Institute: London, UK, 2013.

40. BS EN 12390-3 Testing Hardened Concrete: Part 3: Compressive Strength of Test Specimens; British Standards Institute: London, UK, 2009.

41. Sukontasukkul, P.; Chaikaew, C. Properties of concrete pedestrian block mixed with crumb rubber. Constr. Build. Mater. 2006, 20, 450-457. [CrossRef]

42. Atahan, A.O.; Yücel, A.Ö. Crumb rubber in concrete: Static and dynamic evaluation. Constr. Build. Mater. 2012, 36, 617-622. [CrossRef]

43. He, L.; Ma, Y.; Liu, Q.; Mu, Y. Surface modification of crumb rubber and its influence on the mechanical properties of rubber-cement concrete. Constr. Build. Mater. 2016, 120, 403-407. [CrossRef]

44. Su, H.; Yang, J.; Ling, T.; Ghataora, G.S.; Dirar, S. Properties of concrete prepared with waste tyre rubber particles of uniform and varying sizes. J. Clean. Prod. 2015, 91, 288-296. [CrossRef]

45. BS EN 12390-6 Testing Hardened Concrete: Part 6: Tensile Splitting Strength of Test Specimens; British Standards Institute: London, UK, 2009.

46. BS EN 12390-5 Testing Hardened Concrete: Part 5: Flexural Strength of Test Specimens; British Standards Institute: London, UK, 2009.

47. Xiao, J.; Li, W.; Fan, Y.; Huang, X. An overview of study on recycled aggregate concrete in China (1996-2011). Constr. Build. Mater. 2012, 31, 364-383. [CrossRef]

48. Çakır, Ö. Experimental analysis of properties of recycled coarse aggregate (RCA) concrete with mineral additives. Constr. Build. Mater. 2014, 68, 17-25. [CrossRef]

49. Kaewunruen, S.; Meesit, R.; Mondal, P. Early age dynamic moduli of crumbed rubber concrete for compliant railway structures. J. Sustain. Cem.-Based Mater. 2017, 6, 281-292. [CrossRef] 
50. New York State Assembly. NYS Assembly Priority for Waste Tire Cleanups Finally a Reality. 2003. Available online: http:/ / assembly.state.ny.us/comm/SolidWaste/20030714 (accessed on 14 February 2018).

51. Remennikov, A.M.; Kaewunruen, S. Experimental load rating of aged railway concrete sleepers. Eng. Struct. 2014, 76, 147-162. [CrossRef]

52. Zheng, L.; Sharon Huo, X.; Yuan, Y. Experimental investigation on dynamic properties of rubberized concrete. Constr. Build. Mater. 2008, 22, 939-947. [CrossRef]

53. Kaewunruen, S.; Akono, A.-T.; Remennikov, A.M. Attenuation effect of material damping on impact vibration responses of railway concrete sleepers. GeoMEast 2018, accepted.

54. Kaewunruen, S.; Meesit, R. Sensitivity of crumb rubber particle sizes on electrical resistance of rubberised concrete. Cogent Eng. 2016, 3, 1126937. [CrossRef]

55. Meesit, R.; Kaewunruen, S. Vibration characteristics of micro-engineered crumb rubber concrete for railway sleeper applications. J. Adv. Concr. Technol. 2017, 15, 55-66. [CrossRef]

56. Kaewunruen, S.; Remennikov, A.; Aikawa, A. A numerical study to evaluate dynamic responses of voided concrete railway sleepers to impact loading. In Proceedings of the Australian Acoustical Society Conference 2011, Gold Coast, Australia, 2-4 November 2011; Available online: http:/ / ro.uow.edu.au/engpapers /628/ (accessed on 14 February 2018).

57. Kaewunruen, S.; Rachid, A.; Goto, K. Damping effects on vibrations of railway concrete sleepers. In Proceedings of the 3rd World Multidisciplinary Civil Engineering-Architecture-Urban Planning Symposium, Prigue, Czech, 13-17 June 2016.

58. Xu, Y.; Chung, D. Improving silica fume cement by using silane. Cem. Concr. Res. 2000, 30, $1305-1311$. [CrossRef]

59. Akono, A.-T.; Chen, J.; Kaewunruen, S. Friction and fracture characteristics of engineered crumb-rubber concrete at microscopic lengthscale. Constr. Build. Mater. 2018, 175, 735-745. [CrossRef]

60. Kaewunruen, S.; Remennikov, A.M. Experimental simulation of the railway ballast by resilient materials and its verification by modal testing. Exp. Tech. 2008, 32, 29-35. [CrossRef]

61. Kaewunruen, S.; Remennikov, A.M. Nonlinear finite element modeling of railway prestressed concrete sleeper. In Proceedings of the 10th East Asia-Pacific Conference on Structural Engineering and Construction, EASEC 2010, Bangkok, Thailand, 3-5 August 2006; Volume 4, pp. 323-328.

62. Praticò, F.G.; Giunta, M. Proposal of a Key Performance Indicator for Railway Track Based on LCC and RAMS Analyses. J. Constr. Eng. Manag. 2018, 144, 04017104. [CrossRef]

63. Zhou, Y.; Wang, K.; Lv, K. Comparison of wheel/rail dynamic responses of the rail weld zones between ballasted track and slab track in high-speed railways. J. Adv. Veh. Eng. 2017, 3, 177-181.

64. Kaewunruen, S.; Sussman, J.M.; Matsumoto, A. Grand Challenges in Transportation and Transit Systems. Front. Built Environ. 2016, 2, 4. [CrossRef]

(C) 2018 by the authors. Licensee MDPI, Basel, Switzerland. This article is an open access article distributed under the terms and conditions of the Creative Commons Attribution (CC BY) license (http://creativecommons.org/licenses/by/4.0/). 